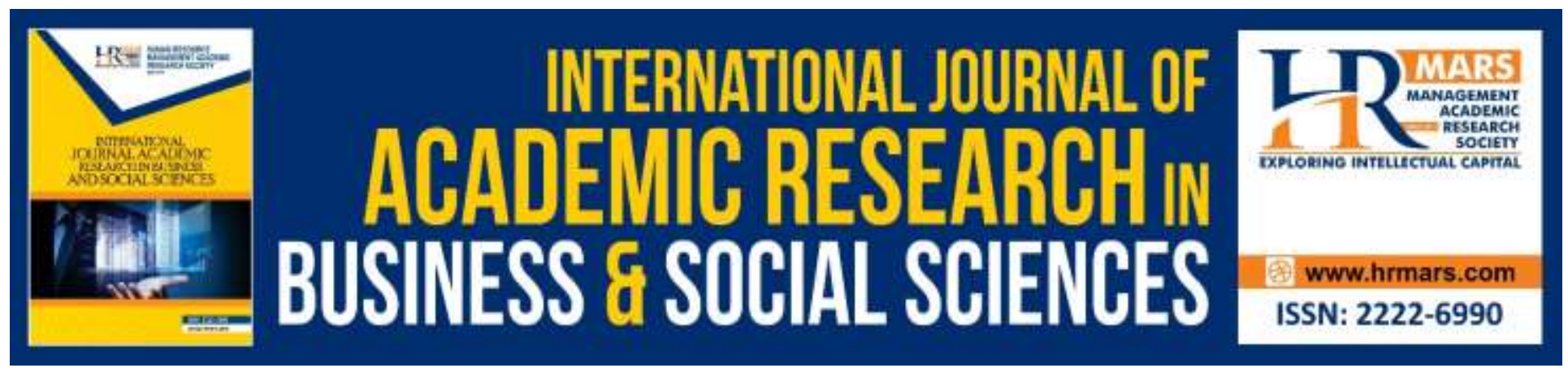

\title{
The Relationship between Job Satisfaction and Organizational Commitment among Lecturers in Heilongjiang Province, China
}

\author{
Wang Guixia, Ramli Basri, Rosnani Jusoh
}

To Link this Article: http://dx.doi.org/10.6007/IJARBSS/v9-i11/6533

DOI: $10.6007 /$ IJARBSS/v9-i11/6533

Received: 22 August 2019, Revised: 10 September 2019, Accepted: 30 September 2019

Published Online: 04 November 2019

In-Text Citation: (GuiXia, Basri, \& Jusoh, 2019)

To Cite this Article: GuiXia, W., Basri, R., \& Jusoh, R. (2019). The Relationship between Job Satisfaction and Organizational Commitment among Lecturers in Heilongjiang Province, China. International Journal of Academic Research in Business and Social Sciences, 9(11), 99-118.

\section{Copyright: (C) 2019 The Author(s)}

Published by Human Resource Management Academic Research Society (www.hrmars.com)

This article is published under the Creative Commons Attribution (CC BY 4.0) license. Anyone may reproduce, distribute, translate and create derivative works of this article (for both commercial and non-commercial purposes), subject to full attribution to the original publication and authors. The full terms of this license may be seen

at: http://creativecommons.org/licences/by/4.0/legalcode

Vol. 9, No. 11, 2019, Pg. 99 - 118

Full Terms \& Conditions of access and use can be found at http://hrmars.com/index.php/pages/detail/publication-ethics 


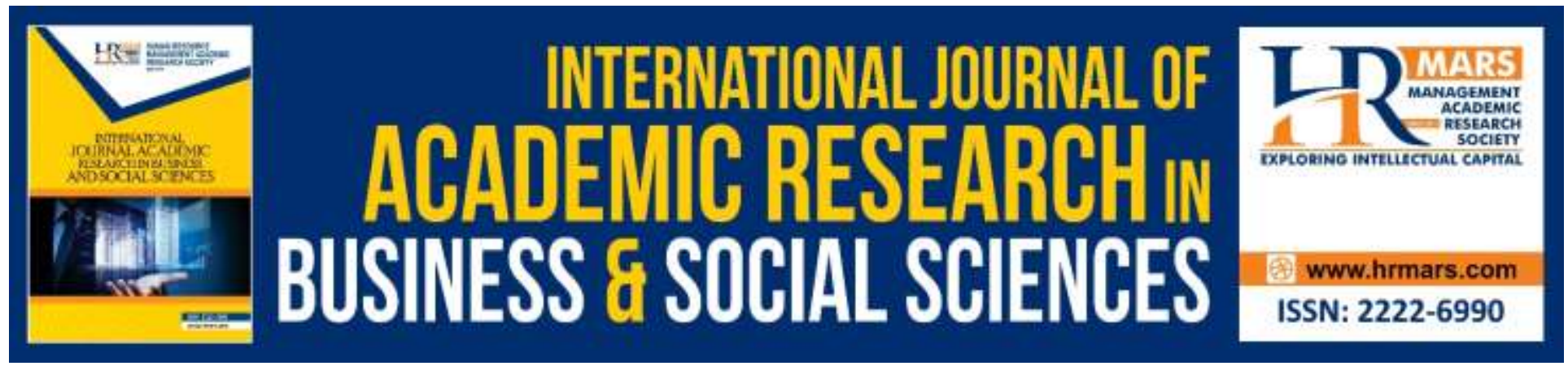

\title{
The Relationship between Job Satisfaction and Organizational Commitment among Lecturers in Heilongjiang Province, China
}

\author{
Wang Guixia, Ramli Basri, Rosnani Jusoh \\ Faculty of Educational Studies, Universiti Putra Malaysia, Selangor Darul Ehsan, Malaysia
}

\begin{abstract}
Text (12pt Font, Font Style: Callibri) this study investigates the relationship between job satisfaction and organizational commitment among the lecturers in Higher Educational Institutions (HEI) in Hei Long Jiang Province, China. From $2529 \mathrm{HEI}$ in China, 83 of them are located in Heilongjiang province. Through simple random sampling, four HEI with total of 221 lecturers in Heilongjiang province took part in this study. This study revealed that the level of job satisfaction and organizational commitment of the lecturers were bordering on the low side. Results also show statistically significant differences between the mean scores of job satisfaction and organizational commitment in terms of gender, marital status, age, highest qualification, job position and years of teaching. Significant correlation was found between some dimensions of job satisfaction and organizational commitment. Implications on the management and recommendation of the studies were discussed thoroughly.
\end{abstract}

Keywords: Job Satisfaction, Organizational Commitment, Lecturer

\section{Introduction}

With the continuous development of China's educational reform, the Higher Educational Institution ( $\mathrm{HEI}$ ) assessment standards and personnel system are constantly changing. The work pressure on HEl lecturers is growing tremendously and this problem is very serious. A study found that more than $90 \%$ of college lecturers have high level of professional pressure, with more than $75 \%$ of the lecturers suffering from long-term chronic fatigue (Xin, 2003). With high level of job stress, lecturers suffered from physical and psychological illnesses such as high blood pressure and anxiety in the workplace. These would have impacts on their work performance such as decreased productivity or careless work, inactive at workplace, lower organizational citizenship behavior, lack of care on the students, frequent absenteeism, and finally lead to turnover or leaving the teaching profession (Sun, Wu \& Wang, 2011). 
Maertz \& Campion (1998) stated that there are turnover costs to be paid by the organization whenever an employee leaves the company. This includes recruitment of replacement, administrative hiring cost, lost productivity due to the time gap between hiring of the replacement, lost productivity due to time needed for the new employee to learn the job, hidden costs in time and money for the training of new employees, social cost due to lower motivation on other employees and even costs of trade secrets being shared by the leaving employee. Thus, job satisfaction plays an important role to retain the employees. Study conducted by Skaalvik \& Skaalvik (2011) found significant negative correlation between job satisfaction and motivation to leave among teachers.

On the other hand, organizational commitment is an important indicator of lecturer's performance at work. Generally, lecturers would have excellent job performance when the organizational commitment is high. This includes being responsible, serious in work, shows enthusiasm and play an active role in his teaching (Cesário \& Chambel, 2017). While there are studies being conducted on job satisfaction and organizational commitment, there is a lack of research on the relationship between the two variables, especially in the field of education (Silverthorne, 2004; Froese \& Xiao, 2012; Bao \& Wang, 2012). Since most of the past studies conducted in China are studying both variables independently, this study aimed to provide the empirical evidence on the relationship between them.

The relationship between job satisfaction and organizational commitment play a significant role to understand the main reason behind why college lecturers leave, and how to improve the relationship between lecturers and schools (Neto, Rodrigues, \& Panzer 2017). In fact, study by Schlesinger and Zornitsky (1991) had shown that dissatisfied employees had low organizational commitment and were three times more likely to leave the job as compared to satisfied employees.

Based on the current local and foreign research about job satisfaction and organizational commitment, there are two main objectives in this study. Firstly, this study would compare the effect of demographic factor on the level of organizational commitment and job satisfaction among lecturers in HEI in China. Secondly, this study would examine organizational commitment and job satisfaction among these lecturers. This is important because organizational commitment is an important indicator for the actual performance of lecturers in $\mathrm{HEI}$. This shed light on how to improve the satisfaction of college lecturers, enhance lecturers a sense of belonging, identify ways for $\mathrm{HEl}$ to retain good lecturers and improve their commitment to the organization. With the huge amount of HEI in China, this study provides useful information to the management.

\section{Literature Review \\ Organizational Commitment}

Hunt \& Morgan (1994) defined organizational commitment as an employee's strong belief in and acceptance of an organizational goal and values, effort on behalf of the organization to reach these goals objectives and strong desire to maintain membership in the organization. Caught \& Shadur (2000, in Bowditch, Buono \& Stewart, 2001) stated that organizational commitment is the commitment of an employee to assist in the attainment of organization goals that involves 
employee's level of identification, involvement and loyalty. Kanter (2008) suggested that when an employee compared the benefits of staying against leaving the organization, it was the level of organizational commitment that determined if he or she would stay or leave. There is always an emotional bond between the employees with their organization after working there for some time. Schneider et al. (2003) argued that organizational commitment would only be achieved when there was consistency between employee's personal goals with organizational goals.

Currently, several models of organizational commitment have been proposed that ranges from single-dimensional model up to four-dimensional model. In single-dimensional model, Mowday, Steers \& Porter (1979) stated that organizational commitment reflected the individual effort towards organization's input and recognition. The commitment is also due the emotional dependence of the staff on the organization (Schneider et al., 2003). Thus, if an employee is reluctant to leave an organization, this is because the employees had feelings for the organization itself. Later, Canadian scholar Meyer et al. (1989) integrated the definition of organizational commitment from the Becker's "continuance commitment" and Porter's "affective commitment" to form a two-dimensional model (Drucker, 2004). Continuance commitment is the attachment of employees to the organization due to the privileges they have in the organization while affective commitment is the psychological affirmation of the employee to the organization.

Later on, Meyer further revised the model to be three-dimensional structure to include normative commitment (Jaros, 2007). Normative commitment is the sense of responsibility and obligation towards the organization due to social constraints and employee's commitment to organizational work. This three-dimensional structure is widely used in the field of academic research and is supported by large number empirical studies. There are several modifications by other researchers that further divide the three-dimensional structures into four dimensional constructs. Swailes (2002) proposed an additional construct of behavioral commitment which included accountability of an employee on their own actions. On the other hand, Blau (2003) believed that it was possible to divide to continuance commitment into cumulative cost commitment that came from huge investment of employee on the organization and limited choice commitment that came from lack of opportunities out there.

The evolution of organizational commitment from a single dimension into multiple dimensions indicates the complexities involved in comprehending organizational commitment. Since there is a lack of substantial studies to confirm the robust and rigidity of the four dimensional structure in organizational commitment, this study employs three-dimensional structure to study the organizational commitment. Bo (2013) identified four factors that correlated positively with organizational commitment among lecturers in China HEI: transformational leadership ( $r=.522)$, self-efficacy $(r=.448)$, goal setting $(r=.557)$ and goal self-concordance $(r=.314)$.

Similar to job satisfaction, organizational commitment of lecturers plays a significant role that directly affects the success and even the survival of the educational institution (Armor, 1995). Hatton (1997) found that there was a close relationship between lecturer commitment and student success. Meyer, Allen \& Allen (2001) added that interpersonal satisfaction and self- 
control would also have a positive impact on organizational commitment while external control factors would have a negative impact instead. Farid et al. (2015) found strong correlation between quality of work life and organizational commitment $(r=.763)$. Xiao \& Wilkins (2015) found strong correlation between organizational commitments with student's perceived teaching quality and student satisfaction in $\mathrm{HEI}$.

Past studies on job satisfaction found that organizational commitment and job satisfaction were positively correlated. Gunlu (2010) found that while intrinsic and extrinsic factors of job satisfaction had no significant effect on continuance commitment, they did have an impact on the affective commitment and normative commitment.

\section{Job Satisfaction}

George and Jones (2008) stated job satisfaction as a combination of employee's feelings and beliefs about their jobs spans across extreme satisfaction to extreme dissatisfaction. Aziri (2011) depicted job satisfaction as a mixture of psychological, physiological and environmental response of employees towards their job. Job satisfaction is also an emotional response that employees have for their work that depended on the gap between expectations of work remuneration and actual remuneration (Langton, Robbins \& Judge, 2013). They would be disappointed if the gap was too large, and the direct response is low level of job satisfaction. There are very few definitions of job satisfaction among Chinese scholars. Xiao-dong (2004) stated job satisfaction as an overall attitude of the individual to his work. This attitude is influenced by personal inner factors, social reference facets and work itself factors.

Despite job satisfaction is a key issue being discussed in many fields, there is still no consensus on the exact definition of job satisfaction. Zangaro \& Soeken (2005) found that job satisfaction did not have a unique dimension to be conceptualized because there were too many studies employed in different institutes and organizations. Most of the definitions of job satisfaction center on the sense or perception of the employees towards fulfilment. In this study, job satisfaction is defined as a form of psychological reaction that employees produce for the different working situations, which include both intrinsic and extrinsic factors. The combination of these two factors forms the general satisfaction of the employee.

In management, job satisfaction has become a gold standard for business goals. Hence, Herzberg (1959) probed into the relationship between motivation and job dissatisfaction (known as hygiene factors) in the workplace (Langton, Robbins \& Judge, 2013). Herzberg's motivationhygiene theory distinguished between the two dimensions of job satisfaction: intrinsic and extrinsic factors. The intrinsic factors are internal aspect that comes from employees themselves that led to self-actualization such as feeling of accomplishment, working process and opportunities for advancement. Meanwhile, the extrinsic factors are external aspect that comes from the organization such as authority, company policies, recognition and job security. This theory proposes job enrichment approach to boost job satisfaction where the task assigned is modified to make it more challenging while the employee is also provided with higher autonomy on the task. 
Hackman and Oldham (1980) later proposed the Job Characteristics Model (JCM) to promote job satisfaction among employees (Schermerhorn, Hunt \& Osborn, 1995). In this model, there are five dimensions of core job characteristics (skill variety, skill identity, skill importance, authority, task feedback) that affect three critical psychological states (meaningfulness of work, responsible for the work outcome and realization of actual results) in the employees. When the employee has the right fit for the core job characteristics, he or she would experience the psychological states that led to the intended outcomes such as excellent work performance and high satisfaction in the task. In general, the employee's work attitude and work enthusiasm mainly depends on the employee's satisfaction with the work, and work attitude and enthusiasm will eventually affect the staff's work performance.

Among the lecturers in China, Munyengabe, Haiyan, Yiyi \& Jiefei (2017) identified six dimensions in job satisfaction: opportunity for advancement, working conditions, co-workers respect, relationship with their supervisor, workload and stress level as well as financial rewards. The study found that promotions and incentives, salary, classroom environment, code of conduct, internal motivation and social factors directly correlated with job satisfaction. However, Du, Lai \& Lo (2010) established a different set of dimensions in job satisfaction. The set of dimensions are career development, school management, teaching and research services, salary, benefits and logistical services, professional reputation, teaching and research facilities, and the work itself. Their study also found that job satisfaction is affected by organizational characteristics (such as school type, school level and academic field), organizational climate, evaluation orientation and school management.

\section{Methodology}

Hong, Shen \& Bruce (2017) reported that there is 5338 post-secondary educational institution in China which comprised of regular $\mathrm{HEl}$, adult institution, 2 or 3 year certificate college and shortcycle vocational technical school. Out from this enormous amount of HEI, 83 of them are located in Heilongjiang province. In this study, four HEI were selected using simple random sampling: Harbin Cambridge University, Qiqihar Teachers College, Chengdong College of Northeast Agricultural University and Heilongjiang Education College. The participants are all full-time lecturers in the selected HEI. A total of 221 participants took part in this study where they complete a self-administered questionnaire. It comprised of 3 sections: demographic, job satisfaction and organizational commitment.

Job satisfaction is measured with 20-items from Minnesota Satisfaction Questionnaire (MSQ) developed by Weiss, Dawis and England (1967) based on the theory of job adaptation. It has two dimensions: intrinsic and extrinsic factors. General satisfaction is the combination of both the two dimensions. Organizational commitment is measured with 24-items from Three-Component Organizational Commitment Questionnaire (OCQ) that was developed by John Meyer \& Natalie Allen (Meyer, Allen\& Allen, 2001). It has three dimensions: affective, continuance and normative. Both instruments use the Likert five-point scoring method. Certain items in OCQ are reversescored item. 
The research instrument had been translated from English to Mandarin. This study adopted content-related evidence as validation method. For the validation of these instruments, the English versions of the instruments were verified by lecturers from UPM while the Chinese version was validated by lecturers from the School of Foreign Languages in China. A pilot study was conducted on 30 lecturers who are working in $\mathrm{HEl}$ in Heilongjiang province. The lecturers were chosen online through random basis. After the pilot study, all the items were found to be easily understood by the respondent. Due to the hectic schedule of lecturers, online questionnaire was sent to lecturers in the selected HEI through email and online messaging tool. The lecturers were informed that they had two months' time frame to complete the questionnaire.

\section{Results}

Out of the 221 lecturers who participated in this study, the majority of lecturers were female 119 (53.85\%), married 159 (71.95\%), between the age group between 31 - 40 years old 99 (44.80\%), with highest qualification of Masters $113(51.13 \%)$, held the position of lecturer $111(50.23 \%)$ and had been teaching for $3-5$ years $116(52.49 \%)$ as shown in Table 1. Table 2 provides the level of job satisfaction and organizational commitment in this study. Overall, the level of job satisfaction was found to be at low level. While the extrinsic factor was at moderate level, the level of intrinsic factor was low. Deeper inspection found that most of the lecturers marked dissatisfied (score of 2 ) in "The chance to do things for other people" and "The freedom to use my own judgement". The sheer amount of workload that comes from assessment standards and personnel system took the toll on their independence to do their core teaching activities.

On the other hand, organizational commitment was found to be at moderate level. Only continuance commitment was found to be at low level. It can be seen that the lecturers continued to be committed to the company neither because of the position that they held nor the welfare they received that were measured by the continuance commitment, but rather they were committed because of psychological affirmation (affective commitment) and social constraints (normative commitment). It was highly possible that due to the nature of work for lecturer to crosscheck the publication of each other, they eventually formed a stable social relationship with one another. Leaving the company would mean a huge loss in the social capital that they invested in. 
INTERNATIONAL JOURNAL OF ACADEMIC RESEARCH IN BUSINESS AND SOCIAL SCIENCES

Vol. 9, No. 11, November, 2019, E-ISSN: 2222-6990 @ 2019 HRMARS

Table 1: Frequency table of the respondents

\begin{tabular}{|c|c|c|c|}
\hline Profile & Category & Frequency & Percentage \\
\hline \multirow[t]{2}{*}{ Gender } & Male & 102 & $46.2 \%$ \\
\hline & Female & 119 & $53.8 \%$ \\
\hline \multirow[t]{2}{*}{ Marital status } & Single & 62 & $28.1 \%$ \\
\hline & Married & 159 & $71.9 \%$ \\
\hline \multirow[t]{4}{*}{ Age } & $<30$ & 58 & $26.2 \%$ \\
\hline & $31-40$ & 99 & $44.8 \%$ \\
\hline & $41-50$ & 46 & $20.8 \%$ \\
\hline & $>50$ & 18 & $8.1 \%$ \\
\hline \multirow[t]{3}{*}{ Highest qualification } & Degree & 69 & $31.2 \%$ \\
\hline & Master & 113 & $51.1 \%$ \\
\hline & $\mathrm{PhD}$ & 39 & $17.6 \%$ \\
\hline \multirow[t]{4}{*}{ Job position } & Assistant lecturer & 34 & $15.4 \%$ \\
\hline & Lecturer & 111 & $50.2 \%$ \\
\hline & Associate Professor & 51 & $23.1 \%$ \\
\hline & Professor & 25 & $11.3 \%$ \\
\hline \multirow[t]{4}{*}{ Years of teaching } & $<2$ years & 49 & $22.2 \%$ \\
\hline & $3-5$ years & 116 & $52.5 \%$ \\
\hline & $6-10$ years & 37 & $16.7 \%$ \\
\hline & $>10$ years & 19 & $8.6 \%$ \\
\hline
\end{tabular}

Table 2: Descriptive statistics of job satisfaction and organizational commitment

\begin{tabular}{lccc}
\hline Research variable & $\mathbf{N}$ & Mean & Standard deviation \\
\hline Intrinsic factor & 12 & 2.86 & 0.52 \\
Extrinsic factor & 6 & 3.25 & 0.51 \\
$\quad$ General job satisfaction & 20 & 3.00 & 0.51 \\
Affective commitment & 8 & 3.38 & 0.54 \\
Normative commitment & 8 & 3.47 & 0.50 \\
Continuance commitment & 8 & 2.83 & 0.53 \\
$\quad$ Organizational commitment & 24 & 3.23 & 0.52 \\
\hline
\end{tabular}

The level of job satisfaction and organizational commitment differ significantly based on demographic factors. Table 3 shows that female lecturers had significantly higher extrinsic factor of job satisfaction compared to male lecturers ( $t=-2.46 ; p<.05)$ as well as higher level of affective commitment ( $t=-5.66 ; p<.01)$. However, there is no significant difference in other dimensions of job satisfaction and organizational commitment in terms of gender. Thus, female lecturers are much more satisfied with the extrinsic factor of the HEI such as management style and competence of their immediate supervisor where the scores are higher. Similarly, female 
lecturers are much more 'emotionally attached' to the organization and feel stronger sense of belonging with the organization.

Table 3: Comparison on Level of Job Satisfaction and Organizational Commitment based on gender

\begin{tabular}{|c|c|c|c|c|c|}
\hline \multirow{2}{*}{ Dimension } & \multicolumn{2}{|c|}{ Male } & \multicolumn{2}{|c|}{ Female } & \multirow{2}{*}{ t-value } \\
\hline & Mean & SD & Mean & SD & \\
\hline Intrinsic factor & 2.84 & 0.58 & 2.89 & 0.64 & -0.58 \\
\hline Extrinsic factor & 3.10 & 0.55 & 3.29 & 0.58 & $-2.45^{*}$ \\
\hline Affective commitment & 3.14 & 0.49 & 3.54 & 0.56 & $-5.66 * *$ \\
\hline Normative Commitment & 3.44 & 0.57 & 3.58 & 0.60 & -1.74 \\
\hline Continuance commitment & 2.84 & 0.61 & 2.85 & 0.56 & 0.94 \\
\hline
\end{tabular}

Table 4 shows the comparison on the level of job satisfaction and organizational commitment between single and married lecturers. In this case, married employees had significantly higher level of intrinsic factor of job satisfaction ( $t=-5.56, p<.01$ ), affective commitment $(t=-3.34$, $\mathrm{p}<.001)$ and continuance commitment $(\mathrm{t}=-2.85, \mathrm{p}<.001)$. However, there is no significant difference in extrinsic factor of job satisfaction and normative commitment in terms of marital status. This shows that married lecturer are much more satisfied with the intrinsic factor of the organization such as chance to do different things and to try own methods of doing the job. Married lecturers also had stronger 'emotional attachment' to the organization and chose to stay due to the cost involved in leaving the organization. After all, these married lecturers have a family to feed and thus, they would naturally be more committed towards their organization in order to secure their jobs.

Table 4: Comparison on Level of Job Satisfaction and Organizational Commitment based on marital status

\begin{tabular}{lccccc}
\hline \multirow{2}{*}{ Dimension } & \multicolumn{2}{c}{ Single } & \multicolumn{2}{c}{ Married } & \multirow{2}{*}{ t-value } \\
\cline { 2 - 5 } & Mean & SD & Mean & SD & \\
\hline Intrinsic factor & 2.50 & 0.65 & 3.01 & 0.53 & $-5.56^{* *}$ \\
Extrinsic factor & 3.16 & 0.55 & 3.21 & 0.59 & -0.61 \\
Affective commitment & 3.16 & 0.52 & 3.43 & 0.57 & $-3.34^{* *}$ \\
Normative Commitment & 3.47 & 0.59 & 3.53 & 0.59 & -0.75 \\
$\begin{array}{l}\text { Continuance } \\
\text { commitment }\end{array}$ & 3.21 & 0.70 & 3.35 & 0.51 & $-2.85^{* *}$ \\
\hline
\end{tabular}

Note: * Significant at .05 level, ** Significant at .01 level

Table 5 shows the comparison on the level of job satisfaction and organizational commitment based on age, highest academic qualification, job position and years of teaching while Table 6 revealed the post-hoc analysis between the groups. In terms of age, data analysis found 
significant difference in both job satisfaction $(F=5.34)$ and organizational commitment $(F=$ 16.56). Those between $31-40$ years old lecturers had significantly higher level of job satisfaction than those $<30$ years old, and those between $41-50$ years old lecturers also had significantly higher level of job satisfaction than those $<30$ years old. On the other hand, lecturers between $41-50$ and $>50$ years old had significantly higher level of organizational commitment than those $<30$ years old. This means older lecturers ( 40 and above) tends to be more satisfied with their job. Similarly, those lecturers between $41-50$ and $>50$ years old had significantly higher level of organizational commitment than those $31-40$ years old. This showed that those older lecturers, above 40 years old, are much more committed to their current HEI than those younger lecturers, below 40 years old.

The age, highest qualification, job position and years of teaching might be closely related with each other. It is highly probable that with older age, the senior lecturers would have higher job position and longer years of teaching. Many lecturers would also pursue postgraduate when they were older and had rich teaching and research experience. Lecturer with higher position in the $\mathrm{HEI}$ would also able to fully utilize the support system provided in the HEI. Hence, there is an observable trend of positive correlation across age, highest qualifications, job positions and years of teaching on the level of job satisfaction and organizational commitment.

In terms of highest academic qualifications of lecturers, significant difference could only be found in the level of job satisfaction $(F=19.70)$ but not organizational commitment. Post Hoc test revealed that lecturers with Master's qualification had significantly higher level of job satisfaction than lecturers with Bachelor's degree, while lecturers with Doctorate qualification had significantly higher level of job satisfaction than lecturers with Master's qualification. Thus, there was an observable trend where level of job satisfaction of lecturer increased when the highest qualification of lecturers changed from Bachelor's degree to Masters to Doctorate.

In terms of job position, there is significant difference in both job satisfaction $(F=6.38)$ and organizational commitment $(F=7.76)$. In-depth analysis also revealed that those with Associate Professor's job position had significantly higher level of job satisfaction than those with only lecturer's job position, and those with Professor's job position also had significantly higher level of job satisfaction than those with only lecturer's job position. However, no significant different was found for the level of job satisfaction between those with Associate Professor and those with Professor. This results show that those lecturer with higher job positions, either as Associate Professor or Professor, would have higher level of job satisfaction. Deeper inspection revealed that majority of those with lecturer job position had a lower satisfaction with the pay and advancement on the job. This is not surprising given that the difference in pay among academicians between entry level and top level in China is the highest where the top level earns almost three times higher than that of entry level (Rumbley, Pacheco \& Altbach, 2008).

For organizational commitment, those with assistant lecturer's job position were found to have significantly lower level of organizational commitment as compared to all other job positions. This shows that those with assistant lecturer's job position are less committed to the work. In other countries, assistant lecturer is also known as Teaching Assistants. While the job scope 
varies between $\mathrm{HEl}$, assistant lecturer primarily in charge of discussion or laboratory sessions only and sometimes assist lecturer in grading assignments or examination (UC San Diego, 2019). Thus, unlike lecturer, assistant lecturer rarely received permanent job in China and had a noticeable lower pay than lecturer. Study by Biggs \& Swailes (2006) and Ntisa, Dhurup \& Joubert (2016) have shown that permanent employees have higher level of job satisfaction and organizational commitment than contracts employees. The rationale behind this is permanent employment usually comes with added benefits and relational entitlement, that linked to continuance commitment of an employee.

Finally, in terms of years of teaching, significant difference was only observed in terms of organizational commitment. Those teaching between $6-10$ years and $>10$ years had significantly higher level of organizational commitment than those teaching $<2$ years. Similarly, those teaching $6-10$ years and $>10$ years also had significantly higher level of organizational commitment than those teaching 3-5 years. This is consistent with another study by Yucel \& Bektas (2012) where older teacher were found to have higher level of organizational commitment than the younger teacher. While there is significant difference in organizational commitment in terms of years of teaching, such is not the case for job satisfaction. There is an observable trend where increasing years of teaching increases the level of job satisfaction and organizational commitment.

Table 5: Comparison on level of Job Satisfaction and Organizational Commitment based on age, highest qualification, job position and years of teaching

\begin{tabular}{cccccccc}
\hline \multirow{2}{*}{ Demographic } & Group & \multicolumn{2}{c}{ Job satisfaction } & \multicolumn{3}{c}{$\begin{array}{c}\text { Organizational } \\
\text { commitment }\end{array}$} \\
\cline { 2 - 8 } Age & & Mean & SD & F & Mean & SD & F \\
\hline (years old) & $31-40$ & 2.62 & 0.59 & $5.34^{* *}$ & 3.09 & 0.43 & $16.56^{* *}$ \\
& $41-50$ & 3.04 & 0.52 & & 3.22 & 0.44 & \\
& $>50$ & 2.83 & 0.38 & & 3.63 & 0.61 & \\
Highest & Bachelor's degree & 2.55 & 0.56 & $19.70^{* *}$ & 3.25 & 0.60 & 0.78 \\
qualification & Master & 2.94 & 0.56 & & 3.35 & 0.50 & \\
& Doctorate & 3.21 & 0.52 & & 3.33 & 0.48 & \\
\hline Job position & Assistant Lecturer & 2.82 & 0.46 & $6.38^{* *}$ & 2.97 & 0.30 & $7.76^{* *}$ \\
& Lecturer & 2.72 & 0.62 & & 3.31 & 0.55 & \\
& Associate professor & 3.08 & 0.52 & & 3.47 & 0.50 & \\
& Professor & 3.12 & 0.60 & & 3.48 & 0.51 & \\
\hline Years of & $<2$ & 2.96 & 0.50 & 2.06 & 3.12 & 0.39 & $10.71^{* *}$ \\
teaching & $3-5$ & 2.79 & 0.58 & & 3.24 & 0.54 & \\
& $6-10$ & 2.84 & 0.65 & & 3.59 & 0.50 & \\
& $>10$ & 3.11 & 0.74 & & 3.68 & 0.48 & \\
\hline
\end{tabular}

Note: * Significant at .05 level, ${ }^{* *}$ Significant at .01 level 
Table 1: Post-hoc comparison between groups on level of Job Satisfaction and Organizational Commitment based on age, highest qualification, job position and years of teaching

\begin{tabular}{|c|c|c|c|c|c|c|c|c|}
\hline \multirow{2}{*}{ Demographic } & \multirow{2}{*}{ Group I } & \multirow{2}{*}{ Group II } & \multicolumn{3}{|c|}{ Job satisfaction } & \multicolumn{3}{|c|}{ Organizational commitment } \\
\hline & & & Mean difference & SE & Sig. & Mean difference & SE & Sig. \\
\hline \multirow{6}{*}{$\begin{array}{c}\text { Age } \\
\text { (years old) }\end{array}$} & $<30$ & $31-40$ & -0.31 & 0.96 & $<.01^{* *}$ & -0.14 & 0.08 & .32 \\
\hline & $<30$ & $41-50$ & -0.42 & 0.11 & $<.01^{* *}$ & -.54 & 0.10 & $<.01 * *$ \\
\hline & $<30$ & $>50$ & -0.21 & 0.15 & .52 & -.64 & 0.13 & $<.01^{* *}$ \\
\hline & $31-40$ & $41-50$ & -0.11 & 0.10 & .69 & -.41 & 0.09 & $<.01^{* *}$ \\
\hline & $31-40$ & $>50$ & 0.10 & 0.15 & .92 & -.50 & 0.12 & $<.01 * *$ \\
\hline & $41-50$ & $>50$ & 0.21 & 0.16 & .56 & -0.09 & 0.13 & .90 \\
\hline \multirow{3}{*}{$\begin{array}{c}\text { Highest } \\
\text { qualification }\end{array}$} & Bachelor's degree & Master & -0.39 & 0.08 & $<.01^{* *}$ & -0.10 & 0.08 & .44 \\
\hline & Bachelor's degree & Doctorate & -0.65 & 0.11 & $<.01 * *$ & -0.09 & 0.11 & .69 \\
\hline & Master & Doctorate & -0.27 & 0.10 & $.03^{*}$ & 0.01 & 0.10 & .99 \\
\hline \multirow[t]{6}{*}{ Job position } & Assistant Lecturer & Lecturer & 0.10 & 0.11 & .80 & -0.34 & 0.10 & $<.01^{* *}$ \\
\hline & Assistant Lecturer & Associate professor & -0.26 & 0.13 & .19 & -0.50 & 0.11 & $<.01^{* *}$ \\
\hline & Assistant Lecturer & Professor & -0.30 & 0.15 & .21 & -0.51 & 0.13 & $<.01^{* *}$ \\
\hline & Lecturer & Associate professor & -0.36 & 0.10 & $<.01 * *$ & -0.16 & 0.09 & .22 \\
\hline & Lecturer & Professor & -0.40 & 0.13 & $<.01^{* *}$ & -0.17 & 0.11 & .41 \\
\hline & Associate professor & Professor & -0.04 & 0.14 & .99 & -0.01 & 0.12 & .99 \\
\hline \multirow{6}{*}{$\begin{array}{l}\text { Years of } \\
\text { teaching }\end{array}$} & $<2$ & $3-5$ & 0.17 & 0.10 & .35 & -0.12 & 0.09 & .50 \\
\hline & $<2$ & $6-10$ & 0.12 & 0.13 & .78 & -0.47 & 0.11 & $<.01^{* *}$ \\
\hline & $<2$ & $>10$ & -0.15 & 0.16 & .80 & -0.56 & 0.13 & $<.01 * *$ \\
\hline & $3-5$ & $6-10$ & -0.05 & 0.11 & .98 & -0.35 & 0.09 & $<.01 * *$ \\
\hline & $3-5$ & $>10$ & -0.31 & 0.15 & .15 & -0.44 & 0.12 & $<.01^{* *}$ \\
\hline & $6-10$ & $>10$ & -0.27 & 0.17 & .38 & -0.09 & 0.14 & .92 \\
\hline
\end{tabular}


Based on Table 7, the study found that both dimensions of job satisfaction are positively correlated to organizational commitment at medium level where $r=.369 ; p<.01$ for intrinsic factor and $r=.511 ; p<.01$ for extrinsic factor. Overall, job satisfaction and organizational commitment was found to be positively correlated at medium level $(r=.439, p<.01)$. This result means that when lecturer has a high level of job satisfaction, the level of organizational commitment would also be at a high level.

Table 7: Correlation between dimensions of job satisfaction with organizational commitment

\begin{tabular}{cc} 
Variables & Organizational commitment \\
\hline Intrinsic factor & $.369^{* *}$ \\
Extrinsic factor & $.511^{* *}$ \\
Job Satisfaction & $.439^{* *}$ \\
\hline
\end{tabular}

Note: * Significant at .05 level, ** Significant at .01 level.

Regression is a technique to determine the best-fitting straight line for a set of data. A multiple regression was run to predict the contribution of the dimensions of job satisfaction on organizational commitment. As shown in Table 8, these dimensions significantly predicted organizational commitment, $F(2,218)=50.273, p<.01, R 2=.316$. Both factors of job satisfaction added significantly to the prediction, $\mathrm{p}<.01$. This indicates that the regression was good as job satisfaction accounted for $31.6 \%$ of the total variation in organizational commitment. It indicated that job satisfaction could be used as a predictor of organizational commitment where extrinsic factor was a stronger predictor as compared to intrinsic factor of job satisfaction among lecturers in $\mathrm{HEl}$ of Heilongjiang province in China.

Standard Regression Equation

Organization commitment $=0.212 *$ Intrinsic $+0.405 *$ Extrinsic factors +1.408

Table 8: Regression Analysis of Job Satisfaction and Organizational Commitment

\begin{tabular}{lcccc}
\hline \multicolumn{1}{c}{ Independent variable } & $\begin{array}{c}\text { Regression } \\
\text { coefficient }\end{array}$ & $\begin{array}{c}\text { Standardized } \\
\text { coefficient }\end{array}$ & $\mathbf{t}$ & Significant \\
\hline Constant term & 1.408 & & 7.290 & $<.01^{* *}$ \\
Intrinsic factors & 0.212 & .244 & 4.179 & $<.01^{* *}$ \\
Extrinsic factors & 0.405 & .442 & 7.546 & $<.01^{* *}$ \\
\hline
\end{tabular}

\section{Discussion}

In the study by Xiu \& Gunderson (2013) in China, they found that female employee tends to be paid less than their male counterparts for the same type of jobs. In fact, there is a worrying trend of substantial and broadening of the gender-wage gap since the past decade. Thus, it is not surprising that female lecturers incline to rate themselves more satisfied in terms of extrinsic 
factor such as income even though they are actually given the same treatment as their male counterparts in this study. It is highly probable that female lecturers forms a better bonding with their fellow colleagues, and thus resulted in significantly higher affective commitment. There is no past studies comparing marital status of lecturers on job satisfaction in China, but studies conducted by Popoola \& Oluwole (2007) in Nigeria \& Kemunto, Adhiambo \& Joseph (2018) in Kenya confirmed that married employees were much happier in their jobs than those who were single. In United States, National Bureau of Economic research also reported that marriage led to better well-being (Rachel, 2016). Marriage provides stability to employee through the unique social support that helps each other.

While older lecturer may not be easily satisfied, they may find it difficult to leave the organization due to lack of employment opportunities and unable to compete with younger lecturer due to rapid development of technology. Older lecturer, especially those $>50$ years old would choose to stay in an organization and reduce unnecessary disruption to their life. This is congruent with another study by Pan et al. (2015) in six universities in Shenyang province, China. Their study identified possible linked between age and job satisfaction. This can be explained with the learning curve of lecturers where they elevate their coping skills and job performance as the time passing by. With better coping skills, older lecturer may be more realistic with their jobs as compared to the younger lecturer. They may also select a positions or roles that suits best to their personality (Bucheli et al., 2010).

This study found that lecturers had significantly higher job satisfaction with higher qualification. Many past studies had similar findings where higher educational level pointed towards higher level of job satisfaction (Gürbüz, 2007). In the field of education, many HEI required lecturers with Doctorate degrees as basic job prerequisite. This is because one of the main tasks of lecturer is to guide the undergraduate students with research. Those lecturers, who had undergone vigorous and intensive research in obtaining their own Doctorate degrees, would definitely have a better understanding of the entire research process itself. Thus, they are more capable in conducting research that led to higher level of job satisfaction. Hence, many studies on job satisfaction suggested continuous professional development to upskill the lecturer and indirectly boost their level of job satisfaction. Even those lecturers who had Doctorate degrees, they would benefit from attending the various continuous professional development courses in the HEI.

Correlation analysis found significant relationship between job satisfaction and organizational commitment. This result was consistent with other findings by Levy \& Williams (1998) with correlations coefficient of $r=.600(p<.05)$, Cheng (2002) with correlation coefficient of $r=.54(p$ $<.05)$ and Ong (2007) with $r=.736$ ( $p$ <.01). While it could not prove any causal relationship, there is indeed a significant correlation between these variables among lecturers in $\mathrm{HEI}$ in China. Standard regression equation also unveiled that the level extrinsic factor of job satisfaction played a more substantial role on the level of organizational commitment, which accounts for almost double than the intrinsic factor of job satisfaction. This also meant that the lecturer's commitment to the organization would remarkably improve if the job satisfaction improve, 
especially in terms of extrinsic factors such as the style of management, how company policies were put into practice and their remuneration based on their increased workload that came from the reformation in assessment standards and personnel system. HEI leaders should play an active role in improving the job satisfaction of the lecturers.

\section{Practical Implications}

There are several changes that could be done to boost the level of job satisfaction of lecturers in $\mathrm{HEI}$ in China and thereby improve their organizational commitment. Since extrinsic factor of job satisfaction is found to be more significant in predicting the organizational commitment, these changes should be done to heighten the level of extrinsic factors. Proper intervention must be carried out based on demography and the current needs of the lecturers.

Firstly, there should be favorable working conditions for lecturers in $\mathrm{HEl}$. A lot of improvement can be done to provide better work setting such as proper air ventilation rather than constant air-conditioned air, sufficient sunlight during the day rather than LED lights and growing plants as interior decoration. Secondly, there should be a better pay system to reduce the lecturer's perception of social injustice. While the exact amount of salary is confidential in any workplace, the job position and lifestyle of a lecturer are plainly visible to all his or her colleagues. The pay system should be transparent with comprehensive criteria. Lecturers should have a clear picture of key performance index that is being evaluated and it should include both tangibles performance such as student's achievement and student's intake as well as intangible performance such as student's satisfaction.

Thirdly, managers ought to develop their leadership skills. Several studies have found the impact of leadership in improving the job satisfaction of lecturers. Nguni, Sleegers \& Denessen (2006) found significant correlation between transformational leadership with job satisfaction of $r=.53$ $(p<.05)$ and organizational commitment of $r=.66(p<.05)$. Transformational leadership is also a leader who seeks to promote the senses of those who are dependents (subordinates) through resorting to the moral ideas and values such as freedom, justice, equality, peace and humanity (Haj \& Jubran, 2016). On the other hand, transactional leader is the leader who exchanges rewards or recognition for cooperation and compliance behaviours consistent with task requirements (Yamarino, 2008). Transactional leaders closely follow the task accomplishments of their followers. Most of the current changes in the reformation in education system are inclined towards transactional leadership (Leithwood \& Jantzi, 2005).

The current system in HEl based on transactional leadership is obsolete as it only punishes inefficient lecturers without setting a vision for the $\mathrm{HEl}$ itself. Though it is important to have fair transactional elements in management, there must be transformational policies in place to help the lecturer to develop and maintain a collaborative, professional organizational culture. This means lecturers should be provided an equal chance to voice out their opinion, observe, critique and plan the reformation together. Norms of collective responsibility and continuous improvement encourage all staff including lecturers to improve themselves. Transformational 
leaders involve staff in collaborative goal setting, reduce staff isolation, use bureaucratic mechanisms to support cultural changes, share leadership with others by delegating power, and actively communicate the school's norms and beliefs.

Finally, since educational level and job position are positively correlates with job satisfaction and organizational commitment, there must be a specifically tailored continuous professional development within the $\mathrm{HEI}$ for lecturers. $\mathrm{HEI}$ can provide incentives to those assistant lecturers and lecturers with only Bachelor's degree or Master's degree to further their studies until Doctorate. Up skilling of lecturers would also lead to greater performance that benefits the students especially in terms of research. Pathway should be clear for assistant lecturer to eventually move on to be a lecturer that receives permanent employment. This could reduce the perception of job security among lecturers.

For lecturers, their motivation for development is enhanced when they internalize the goals for professional growth that led to greater job satisfaction. This process would then improve their commitment not only to the organization but also to the mission and vision. For leaders, continuous professional development would sharpen their leadership skills. When leaders are able to empower their followers with a role in improvement plans, the plan would be executed much more successfully and the followers are more willing to work on it. In short, in order for China's educational reformation to be successful, there should be changes to alleviate the job satisfaction and organizational commitment of the lecturers. Without such, the entire reformation of education in China may be impossible or progress very slowly.

\section{Recommendation for Future Research}

The current study presented the correlation between job satisfaction and organizational commitment at a moderate level. Further studies should focus on other moderating variables that could explain for the variation in the correlation such as job stress (Cheng, 2002), organizational learning (Rose, Kumar \& Pak, 2009), leadership (Nguni, Sleegers \& Denessen, 2006) and emotional exhaustion (Skaalvik \& Skaalvik, 2011). This would provide an overall picture of the relationship between all these variables on the organizational commitment that would determine the work performance in the reformation.

Further studies could also be carried out on a larger population given the sheer massive amount of lecturers in the $\mathrm{HEI}$ in China. This current study of $4 \mathrm{HEI}$ would not be sufficient to generalize the possible relationship in the other $5334 \mathrm{HEl}$. Since China is a big country with over 9.597 million $\mathrm{km} 2$, those HEl from different geographical locations would be very different in the environment and the culture. Klassen, Usher and Bong (2010) found that job satisfaction differs significantly across different cultures.

\section{Conclusion}

This study demonstrates the relationship between job satisfaction and organizational commitment from an empirical point of view and provides an empirical basis for future academic 
research. This study provides further evidence for management to improve job satisfaction and organizational commitment of the lecturers in China. Since most of the past studies conducted in China are studying both variables independently, this study provided the empirical evidence on the relationship between them. However, this study has its own limitations in the selection of variables. With the huge number of higher educational institution, it is hopeful that further studies could be conducted in different provinces. This would provide a clearer picture for the administrator on developing suitable policy that could strengthen lecturer's job satisfaction.

\section{Corresponding Author}

Ramli Basri is associate professor at the Faculty of Educational Studies, Universiti Putra Malaysia, Selangor Darul Ehsan, Malaysia. Email: ramlibasri@upm.edu.my

\section{References}

Aziri, B. (2011). Job satisfaction: A literature review. Management Research \& Practice, 3(4). Armor, D. J. (1995). Can desegregation alone close the achievement gap. Education Week, 14, 41. Bao, W., \& Wang, J. (2012). Stress in the Ivory Tower: An Empirical Study of Stress and Academic Productivity among University Faculty in China [J]. Peking University Education Review, 1, 014.

Biggs, D., \& Swailes, S. (2006). Relations, commitment and satisfaction in agency workers and permanent workers. Employee Relations, 28(2), 130-143.

Blau, G. (2003). Testing for a four-dimensional structure of occupational commitment. Journal of Occupational and Organizational Psychology, 76, 469-488.

Bo, Y. (2013). The influence study of transformational leadership in university on teachers' organizational commitment: The construction and verification of a theoretical model. Canadian Social Science, 9(4), 126.

Bowditch, J. L., Buono, A. F., \& Stewart, M. M. (2001). A primer on organizational behavior. New York, NY: Wiley.

Bucheli, M., Melgar, N., Rossi, M., \& Smith, T. W. (2010). Job satisfaction and the individual educational level, re-assessing their relationship. Documento de Trabajo/FCS-DE; 11/10.

Cesário, F., \& Chambel, M. J. (2017). Linking organizational commitment and work engagement to employee performance. Knowledge and Process Management, 24(2), 152-158.

Cheng, F.K. (2002). Occupational stress, organizational commitment, career commitment, job satisfaction and withdrawal cognition among school teachers (Unpublished doctoral dissertation). University Putra Malaysia, Malaysia

Drucker, P. (2004). Organization behaviour. Management Today.

Du, P., Lai, M., \& Lo, L. N. (2010). Analysis of job satisfaction of university professors from nine Chinese universities. Frontiers of Education in China, 5(3), 430-449.

Farid, H., Izadi, Z., Ismail, I. A., \& Alipour, F. (2015). Relationship between quality of work life and organizational commitment among lecturers in a Malaysian public research university. The Social Science Journal, 52(1), 54-61.

Froese, F. J., \& Xiao, S. (2012). Work values, job satisfaction and organizational commitment in China. The International Journal of Human Resource Management, 23(10), 2144-2162. 
George, J.M., \& Jones, G.R. (2008). Understanding and Managing Organizational Behavior. Fifth Edition. Upper Saddle River: New Jersey, Pearson Prentice Hall.

Gunlu, E., Aksarayli, M., \& ŞahinPerçin, N. (2010). Job satisfaction and organizational commitment of hotel managers in Turkey. International Journal of Contemporary Hospitality Management, 22(5), 693-717.

Gürbüz, A. (2007). An assessment on the effect of education level on the job satisfaction from the tourism sector point of view.

Hatton, S. A. (1997). Teacher organizational commitment in high performing, low socioeconomic status, border elementary schools (Texas)(CD-ROM). Abstract from: ProQuest File: Dissertation Abstracts International Item, 58(01).

Haj, S. J., \& Jubran, A. M. (2016). The Extent of Principals' Application of the Transformational Leadership and Its Relationship to the Level of Job Satisfaction among Teachers of Galilee Region. Journal of Education and Practice, 7(11), 114-119.

Hong, S., Shen, H., \& Bruce, J. (2017). Higher Education Finance in China.

Hunt, S. D., \& Morgan, R. M. (1994). Organizational commitment: one of many commitments or key mediating construct? Academy of Management Journal, 37(6), 1568-1587.

Jaros, S. (2007). Meyer and Allen model of organizational commitment: Measurement issues. The Icfai Journal of Organizational Behavior, 6(4), 7-25.

Kanter, R. M. (2008). Men and women of the corporation: New edition. Basic books.

Kemunto, M. E., Adhiambo, R. P., \& Joseph, B. (2018). Is Marital Status a Predictor of Job Satisfaction of Public Secondary School Teachers?.

Klassen, R. M., Usher, E. L., \& Bong, M. (2010). Teachers' collective efficacy, job satisfaction, and job stress in cross-cultural context. The Journal of Experimental Education, 78(4), 464-486.

Langton, N., Robbins, S. P., \& Judge, T. A. (2013). Fundamentals of organizational behaviour. Pearson Education Canada.

Levy, P. E., \& Williams, J. R. (1998). The role of perceived system knowledge in predicting appraisal reactions, job satisfaction, and organizational commitment. Journal of Organizational Behavior: The International Journal of Industrial, Occupational and Organizational Psychology and Behavior, 19(1), 53-65.

Leithwood, K., \& Jantzi, D. (2005). Transformational leadership. The essentials of school leadership, 31-43.

Maertz, C. P., \& Campion, M. A. (1998). Turnover. International review of industrial and organizational psychology, 13, 49-82.

Meyer, J., Allen, N. J., \& Allen, N. J. (2001). Organizational commitment. Personnel psychology and human resource management: A reader for students and practitioners, 289-342.

Munyengabe, S., Haiyan, H., Yiyi, Z., \& Jiefei, S. (2017). Factors and Levels Associated with Lecturers' Motivation and Job Satisfaction in a Chinese University. Eurasia Journal of Mathematics, Science and Technology Education, 13(10), 6415-6430.

Nguni, S., Sleegers, P., \& Denessen, E. (2006). Transformational and transactional leadership effects on teachers' job satisfaction, organizational commitment, and organizational citizenship behavior in primary schools: The Tanzanian case. School effectiveness and school improvement, 17(2), 145-177. 
Neto, R. D. C. A., Rodrigues, V. P., \& Panzer, S. (2017). Exploring the relationship between entrepreneurial behavior and teachers' job satisfaction. Teaching and Teacher Education, 63, 254-262.

Ntisa, A. A., Dhurup, M., \& Joubert, P. A. (2016). The contract of employment status and its influence on the job satisfaction of academics within South African Universities of technology. International Journal of Social Sciences and Humanity Studies, 8(2), 180-195.

Ong, G. P. (2007). The effect of organizational learning on organizational commitment, job satisfaction and work performance (Unpublished doctoral dissertation). University Putra Malaysia, Malaysia.

Pan, B., Shen, X., Liu, L., Yang, Y., \& Wang, L. (2015). Factors associated with job satisfaction among university teachers in northeastern region of China: A cross-sectional study. International journal of environmental research and public health, 12(10), 12761-12775.

Popoola, S. O., \& Oluwole, D. A. (2007). Career commitment among records management personnel in a state civil service in Nigeria. Records management journal, 17(2), 107-116.

Rachel, G. (2016). 7 Ways being married makes you more successful. Business Insider Malaysia. Retrieved online from https://www.businessinsider.my/how-being-married-makes-youmore-successful-2016-7/? $r=U S \& \mid R=T$

Rumbley, L., Pacheco, I. F., \& Altbach, P. G. (2008). International comparison of academic salaries: An exploratory study. Chestnut Hill, MA: Boston College Center for International Higher Education.

Rose, R. C., Kumar, N., \& Pak, O. G. (2009). The effect of organizational learning on organizational commitment, job satisfaction and work performance. Journal of Applied Business Research, 25(6), 55.

Schermerhorn, J. R., Hunt, J. G., \& Osborn, R. N. (1995). Basic organizational behavior. Hobken, NJ: J. Wiley.

Schneider, B., Hanges, P. J., Smith, D. B., \& Salvaggio, A. N. (2003). Which comes first: employee attitudes or organizational financial and market performance?.Journal of applied psychology, 88(5), 836.

Schlesinger, L. A., \& Zornitsky, J. (1991). Job satisfaction, service capability, and customer satisfaction: An examination of linkages and management implications. Human Resource Planning, 14(2).

Silverthorne, C. (2004). The impact of organizational culture and person-organization fit on organizational commitment and job satisfaction in Taiwan. Leadership \& Organization Development Journal, 25(7), 592-599.

Skaalvik, E. M., \& Skaalvik, S. (2011). Teacher job satisfaction and motivation to leave the teaching profession: Relations with school context, feeling of belonging, and emotional exhaustion. Teaching and teacher education, 27(6), 1029-1038.

Sun, W., Wu, H., \& Wang, L. (2011). Occupational stress and its related factors among university teachers in China. Journal of occupational health, 53(4), 280-286.

Swailes, S. (2002). Organizational commitment: a critique of the construct and measures. International journal of management reviews, 4(2), 155-178. 
UC San Diego (2019). Teaching Assistants, Tutors and Readers. SCRIPPS Institution of Oceonography. Retrieved online from https://scripps.ucsd.edu/education/current/teaching-assistants

Xin, P. A. N. (2003). Quan Zheng liang, Qian Yu yan; Relation between Mental Health and Occupational Stress among College Teachers [J]. Chinese Journal of Health Education, 10.

Xiu, L., \& Gunderson, M. (2013). Gender earnings differences in china: base pay, performance pay, and total pay. Contemporary economic policy, 31(1), 235-254.

Xiao-dong, X. U. (2004). A Study on the Relationship between the Mental Worker Job IntrinsicExtrinsic Stress and Job Satisfaction [J]. Chinese Journal of Applied Psychology, 3.

Xiao, J., \& Wilkins, S. (2015). The effects of lecturer commitment on student perceptions of teaching quality and student satisfaction in Chinese higher education. Journal of Higher Education Policy and Management, 37(1), 98-110.

Yammarino, F. J., Dionne, S. D., Schriesheim, C. A., \& Dansereau, F. (2008). Authentic leadership and positive organizational behavior: A meso, multi-level perspective. The Leadership Quarterly, 19(6), 693-707.

Yucel, I., \& Bektas, C. (2012). Job satisfaction, organizational commitment and demographic characteristics among teachers in Turkey: Younger is better. Procedia-Social and Behavioral Sciences, 46, 1598-1608.

Zangaro, G. A., \& Soeken, K. L. (2007). A meta-analysis of studies of nurses' job satisfaction. Research in nursing \& health, 30(4), 445-458. 